\title{
Estimation of electrical conductivity of a soil solution from the monitored TDR data and an extracted soil solution
}

\author{
Katsutoshi Seki ${ }^{*}$, Teruhiko Miyamoto ${ }^{2}$, and Yukiyoshi Iwata ${ }^{2}$ \\ ${ }^{1}$ Natural Science Laboratory, Toyo University, 5-28-20 Hakusan, Tokyo 112-8606, Japan \\ ${ }^{2}$ Agricultural Environment Engineering Research Division, Institute for Rural Engineering, NARO, 2-1-6 Kannondai, \\ Tsukuba, Ibaraki 305-8609, Japan
}

Received April 24, 2018; accepted November 4, 2018

\begin{abstract}
In order to establish sustainable agricultural practices and to avoid excess fertiliser application, it appears important to understand the process of water and solute transport. With a view to analysing transport through the soil, based on the data obtained by means of time domain reflectometry, the relationship between the volumetric water content, the apparent electrical conductivity, and the soil solution electrical conductivity should be known. This paper proposes a new method for estimating the three parameters relationship by optimising the parameters obtained through Rhoades model with the Levenberg-Marquardt method. The proposed method systematically determines the initial parameter set required to conduct nonlinear optimisation. The method was used to estimate the continuous apparent electrical conductivity data based on the time domain reflectometry dataset, obtained from the field and occasional measurement of soil solution electrical conductivity data of the soil water, which was extracted by means of a suction sampler installed in the field. Compared with the conventional method where the parameters of Rhoades model are calibrated with a 2-step linear regression by means of laboratory experiment, the soil solution electrical conductivity estimated with the proposed method was closer to the field data, yielding smaller root mean square error values. Supplementary use of the dataset obtained through a laboratory experiment under dry and wet conditions improved the accuracy of parameter estimation.

Keyw ords: time domain reflectometry, Rhodes model, parameter estimation
\end{abstract}

\section{INTRODUCTION}

In order to establish sustainable agricultural practices and to avoid excess fertiliser application, it is important to understand the process of water and solute transport. Measuring the volumetric water content $(\theta)$ and the apparent soil electrical conductivity $\left(E C_{a}\right)$ under field conditions is generally required for this purpose. Time domain reflec-

\footnotetext{
*Corresponding author e-mail: seki_k@toyo.jp
}

tometry (TDR) is widely used for determining $\theta$ and $E C_{a}$ simultaneously (Noborio, 2001). Moreover, multi-sensor probes have also been developed recently to assess $\theta$ and $E C_{a}$, with continuous and non-destructive measurements (Scudiero et al., 2012; Vaz et al., 2013). By using these measurement techniques, we can easily obtain the $\theta$ and $E C_{a}$ data in fields.

It does not appear practical to assess solute transport in soil using $E C_{a}$ under transient conditions because of the strong dependence of $E C_{a}$ on $\theta$. Therefore, $E C_{a}$ must be related to the soil solution electrical conductivity $\left(E C_{w}\right)$ so as to estimate the solution concentration under transient conditions with varying water content. The physico-empirical and / or theoretical models describing the dependence of $E C_{a}$ on $E C_{w}$ and $\theta$ (e.g. Rhoades et al., 1976; Rhoades et al., 1989; Mualem and Friedman, 1991; Malicki and Walczak, 1999; Hilhorst, 2000) are used to estimate $E C_{w}$ for a given combination of the measured $E C_{a}$ and $\theta$ in a particular soil (Mallants et al., 1996; Risler et al., 1996; Das et al., 1999; Muñoz-Carpena et al., 2005; Miyamoto et al., 2015).

Laboratory calibration experiments are conducted using repacked soil columns to obtain model parameters for the $E C_{w}-E C_{a}-\theta$ relationship (Heimovaara, 1995; De Neve et al., 2000; Muñoz-Carpena et al., 2005; Wilczek et al., 2012; Miyamoto et al., 2015). However, this calibration method is not suitable for field measurements because soils in the field are often structured and more naturally heterogeneous than the uniformly repacked soil columns. Moreover, the calibration procedure of a 2 -step linear regression requires that multiple datasets of precisely the same water content or the same electrical conductivity are obtained, which is hardly available from the field data. Das et al. (1999)

(C) 2019 Institute of Agrophysics, Polish Academy of Sciences 
proposed a field calibration procedure, which is an in situ mass balance approach with a TDR probe installed vertically on the soil surface. This calibration procedure, however, can be only applied to the top soil layer.

Sensor pairing is a field measurement method of the soil water characteristic (Baumgartner et al., 1994). The paired sensors, such as neutron moisture meter access tubes or TDR probes, and tensiometers are often used to simultaneously determine $\theta$ and the matric potential $(\psi)$. As a result, the $\theta-\psi$ values are obtained. In an similar way, the simultaneous measurements of $E C_{w}-E C_{a}-\theta$ values, using soil solution samplers and TDR probes, will also be a useful method for an in situ determination of the $E C_{w}-E C_{a}-\theta$ relationship.

The objective of this study is to develop a method to identify the parameters of Rhodes model (Rhoades et al., 1976 ) for the $E C_{w}-E C_{a}-\theta$ relationship based on a dataset of the $E C_{w}, E C_{a}$ and $\theta$ values which are measured in the field. To this end, we have designed a calculation procedure by adopting the Levenberg-Marquardt optimisation method (Marquardt, 1963), which has become a standard in nonlinear least-square fitting among both soil scientists and hydrologists (Šimůnek and Hopmans, 2002; Seki, 2007). We have compared the $E C_{w}$ estimated from the proposed method with the one obtained from the conventional method of a 2-step linear regression, as shown by Miyamoto et al. (2015). In addition, we have discussed a supplemental use of the dataset of $E C_{w}, E C_{a}$ and $\theta$ obtained through a laboratory experiment to improve the accuracy of the proposed method.

\section{MATERIALS AND METHODS}

The field data published in Miyamoto et al. (2015) were used in this study. The field experiment was carried out in the experimental field at the National Agriculture and Food Research Organization in Tsukuba, Japan. The soil at that site was an Andosol (IUSS Working Group, 2014). The soil profile was divided into two layers; the boundary between the surface and subsurface layers (topsoil and subsoil) was at $0.5 \mathrm{~m}$ depth. The bulk densities of topsoil and subsoil were 710 and $630 \mathrm{~kg} \mathrm{~m}^{-3}$, respectively. Saturated hydraulic conductivities of these soils were 35.0 and $30.0 \mu \mathrm{m} \mathrm{s}^{-1}$, respectively. The soil water retention curves of topsoil and subsoil are shown in Fig. 1. The field was fertilised with $20.0 \mathrm{~g} \mathrm{~m}^{-2}$ of $\mathrm{N}, 8.7 \mathrm{~g} \mathrm{~m}^{-2}$ of $\mathrm{P}$ and $16.6 \mathrm{~g} \mathrm{~m}^{-2}$ of $\mathrm{K}$, used as chemical fertilisers, on 25 December 2007. The ground surface was maintained in an unplanted condition throughout the field experiment until 31 August 2008.

Dielectric permittivity of the soil $\left(\varepsilon_{a}\right)$ and $E C_{a}$ were measured with TDR probes installed horizontally into pit faces at three locations and at three depths $(0.2,0.4$, and $0.6 \mathrm{~m}$, respectively) during the experimental period, in order to detect the TDR waveforms reflected from the probes. A cable tester (Tektronix, 1502B) was used to detect the

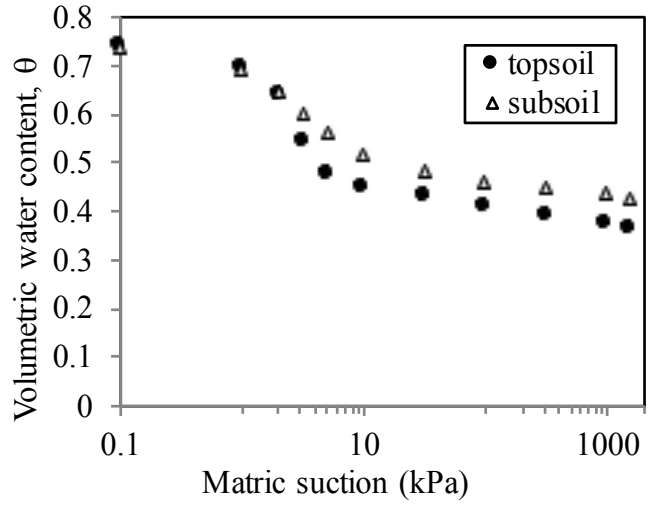

Fig. 1. Soil water retention curves of topsoil and subsoil in the experimental field.

time domain of the electromagnetic wave, along with the probes. The observed data were recorded using a portable computer every hour. A copper-constantan thermocouple was installed in the central pit at each of the three depths to measure temperature in a continuous manner, which was recorded by means of a datalogger (Campbell Scientific Inc., CR10X) every hour. The relationship between $\varepsilon_{a}$ and $\theta$ was calibrated through a laboratory experiment, and the values of $\varepsilon_{a}$ were converted into the respective values of $\theta$ under field conditions, using the calibration equation. The measured $E C_{a}$ values were calibrated to the value at $25^{\circ} \mathrm{C}$ with the temperature correction factor taken from Heimovaara et al. (1995).

The porous ceramic soil solution samplers were also buried at three depths. Two samplers were buried at each depth. The soil solution was sampled once to three times a month by applying a suction of 50-70 $\mathrm{kPa}$ during the field experiment. $E C_{w}$ was measured for each extracted soil solution using a portable EC meter (HORIBA ltd., Twin Cond). The average of 2 measured values obtained for each soil depth was used in the analysis. As a result, during 8 months of the measured period, 17 data points of $E C_{w}$ in the field were obtained.

Figure $2 \mathrm{~A}$ shows the process of estimating $E C_{w}$ by means of the conventional method. Rhoades et al. (1976) derived the following equation:

$$
E C_{a}=E C_{w} \theta T+E C_{s},
$$

where: $T$ is the transmission coefficient which accounts for the tortuous nature of the current lines and any decreases in the mobility of the ions near the solid-liquid and liquidgas interfaces, and $E C_{s}$ is the surface conductivity via exchangeable cations. They assumed that $T$ is linear to $\theta$, based on the empirical relationship by Gupta and Hanks (1972), which is as follows:

$$
T=a \theta+b,
$$

where: $a$ and $b$ are constants. Using the Eq. (2), the following equation was derived: 
(A)

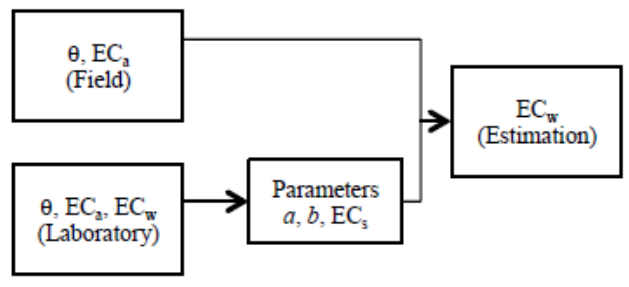

(B)

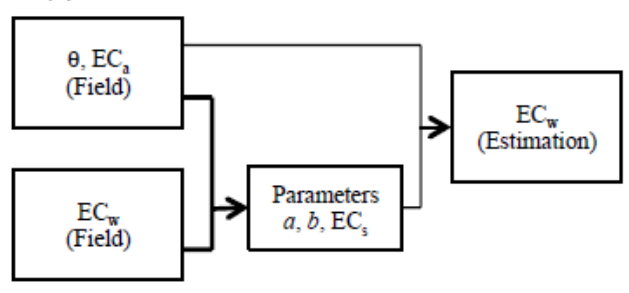

Fig. 2. Estimation of electrical conductivity of the soil solution $\left(E C_{w}\right)$. (A) The conventional method (Miyamoto et al., 2015) (B) The method proposed in this study.

$$
E C_{a}=(a \theta+b) \theta E C_{w}+E C_{s} .
$$

The conventional method is a 2 -step linear regression. In the first linear regression, for different sets of water content (e.g., $\theta=0.35,0.40,0.50,0.60$ for the experiment conducted by Miyamoto et al., 2015) the relationships between $E C_{w}$ and $E C_{a}$ were written, and the fitted lines with slope $S=(a \theta+b) \theta$ and intersect $E C_{s}$ were obtained. In the second linear regression, $S / \theta$ was plotted against $\theta$, and the linear fit yielded $a$ and $b$. Finally, the Rhoades parameter set, $a, b$ and $E C_{s}$ was used to estimate $E C_{w}$ based on the measured $\theta$ and $E C_{a}$ from Eq. (3). The conventional method requires that multiple datasets of precisely the same water content are plotted in the first regression to obtain parameters for the second regression.

In the proposed method, the field-obtained values of $\theta$, $E C_{a}$ and $E C_{w}$ were basically used to determine $a, b$ and $E C_{s}$ of Rhoades model (Fig. 2B), with a successive optimisation technique as follows. In the present study, we used $17 E C_{w}$ data obtained from soil solution samplers. By coupling the data with the $\theta$ and $E C_{a}$ values measured with TDR probes in the field, both at the same depth and on the same day, we obtained 17 sets of measured data $\left(\theta, E C_{a}, E C_{w}\right)$, which were then used to estimate the parameter set $\left(a, b, E C_{s}\right)$. Eq. (3) can be transformed as follows:

$$
\frac{E C_{a}-E C_{s}}{E C_{w} \theta}=a \theta+b
$$

Equation (4) shows the linear relationship between $\theta$ and $\left(E C_{a}-\mathrm{EC}_{\mathrm{s}}\right) / E C_{w} \theta$. At first, $E C_{s}$ was assumed to be 0.25 $\mathrm{dS} \mathrm{m} \mathrm{m}^{-1}$, one of the values obtained in Rhoades et al. (1976), and the parameters $a$ and $b$ were obtained with the linear regression of equation (4). Then, $a, b$ and $E C_{s}$ were opti- mised with Eq. (3) simultaneously by the non-linear least square optimisation algorithm of Levenberg-Marquardt method (Marquardt, 1963).

Let the independent variable vector $\boldsymbol{x}$ in Eq. (3) be defined by $\boldsymbol{x}=\left(x_{1}, x_{2}\right)=\left(\theta, E C_{w}\right)$, and the parameter vector $\boldsymbol{p}$ be defined by $\boldsymbol{p}=\left(p_{1}, p_{2}, p_{3}\right)=\left(a, b, E C_{s}\right)$. The model Eq. (3) is rewritten as:

$$
f(\boldsymbol{x}, \boldsymbol{p})=\left(p_{1} x_{1}+p_{2}\right) x_{1} x_{2}+p_{3} .
$$

Let the data points be denoted by:

$$
\left(Y_{i}, \boldsymbol{X}_{i}\right)=\left(Y_{i}, X_{1 i}, X_{2 i}\right), i=1,2, \ldots, m,
$$

where: $X_{1 i}, X_{2 i}$, and $Y_{i}$ are the $i$-th data point of $\theta, E C_{w}$, and $E C_{a}$, respectively. The objective function of the least square analysis $O(\boldsymbol{p})$ is:

$$
O(\boldsymbol{p})=\sum_{i=1}^{m} w_{i}\left[Y_{i}-f\left(\boldsymbol{X}_{i}, \boldsymbol{p}\right)\right]^{2},
$$

where: the weights $w_{i}$ are normally set to 1 (unity). The Levenberg-Marquardt algorithm efficiently solves parameter vector $\boldsymbol{p}$ so that $O(\boldsymbol{p})$ is minimised. The LevenbergMarquardt method requires an initial estimate of parameter vector $\boldsymbol{p}$. It then updates the estimate iteratively to find the final estimate of $\boldsymbol{p}$. In the iterative procedure, vector $\boldsymbol{p}$ may not converge to a proper value when the initial estimate of the parameter is not close enough to the final solution. Therefore, selecting a reasonably good set of the initial parameter is a very important step for this algorithm. In the proposed method, the initial estimate of parameter vector $\boldsymbol{p}$ can be obtained systematically by the regression of Eq. (4) as described above.

The difference in the two methods shown in Fig. 2 concerns the methods of obtaining the Rhoades parameters (parameter vector $\boldsymbol{p}$ ). The advantage of using the proposed method is that it does not require separate laboratory experiments that are both time-consuming and tedious. The conventional method requires calibration curves of the $E C_{w}-E C_{a}$ relationship for the same $\theta$ values. Such data are not usually available in the field, and thus the conventional method can only be used with laboratory data. The proposed method does not require that the $\theta$ values be exactly controlled, and thus the field data can be directly used for obtaining Rhoades parameters. Moreover, as the conventional method simultaneously optimises all the parameters, it may require a smaller dataset for estimation. To verify whether the proposed method requires a smaller amount of data, we also performed calculation with smaller datasets. From each month between January and August, one measuring dataset of $\left(\theta, E C_{a}, E C_{w}\right)$ was selected so that the interval between the data points was around 30 days, and 8 data were used in the analysis.

The algorithm was implemented in the mathematicsoriented programming language of GNU Octave. The programme first fits the given dataset of $\theta, E C_{w}$ and $E C_{a}$ to Eq. (4) to get the initial estimate of the parameter set, 
and then the initial parameter set is successively optimised with the iterative procedure of the Levenberg-Marquardt method to get the final parameter set of $a, b$ and $E C_{s}$. In the programme, the parameters were constrained with $a>0$ and $0<E C_{s}<\min \left(E C_{a}\right)$.

\section{RESULTS AND DISCUSSION}

Table 1 shows the parameters used in Eq. (3) that were estimated on the basis of the $E C_{w}$ values of the extracted soil solution, and $\theta$ and $E C_{a}$ were measured with TDR probes using the developed method (Fig. 2B). Figure 3 shows the relationship between the measured and estimated $E C_{a}$ with parameters in Table 1 of the 3 TDR probes at each depth. The agreement between the measured and estimated $E C_{a}$ is not very good, compared to the laboratory calibration experiment outlined by Miyamoto et al. (2015), because the field experiment could not be controlled to the same extent as the laboratory experiment. However, many plots were found to be close to the identity line.

Figure 4 shows the change in the estimated $E C_{w}$ that was calculated from the $\theta$ and $E C_{a}$ values measured with TDR probes, and parameters in Table 1, compared with the $E C_{w}$ directly measured from the soil solution. The estimation at topsoil ( $0.2 \mathrm{~m}$ depth) was not successful because the

Table 1. Estimated parameters with field extracted soil solution and field measured TDR data

\begin{tabular}{lccccccccc}
\hline Depth & \multicolumn{3}{c}{$0.2 \mathrm{~m}$} & \multicolumn{3}{c}{$0.4 \mathrm{~m}$} & \multicolumn{3}{c}{$0.6 \mathrm{~m}$} \\
\hline Probe ID & $2 \mathrm{~A}$ & 2B & 2C & $4 \mathrm{~A}$ & $4 \mathrm{~B}$ & $4 \mathrm{C}$ & $6 \mathrm{~A}$ & $6 \mathrm{~B}$ & $6 \mathrm{C}$ \\
\hline$a$ & 3.7333 & 4.2508 & 5.1457 & 0.4019 & 0.3292 & 0.3689 & 0.0011 & 0.0000 & 0.0001 \\
$b$ & -1.5934 & -2.0348 & -2.3268 & 0.5228 & 0.1762 & 0.1433 & 1.0683 & 1.0408 & 1.0429 \\
$E C_{s}$ & 0.0463 & 0.0182 & 0.0000 & 0.0000 & 0.0000 & 0.0000 & 0.0046 & 0.0000 & 0.0000 \\
\hline
\end{tabular}
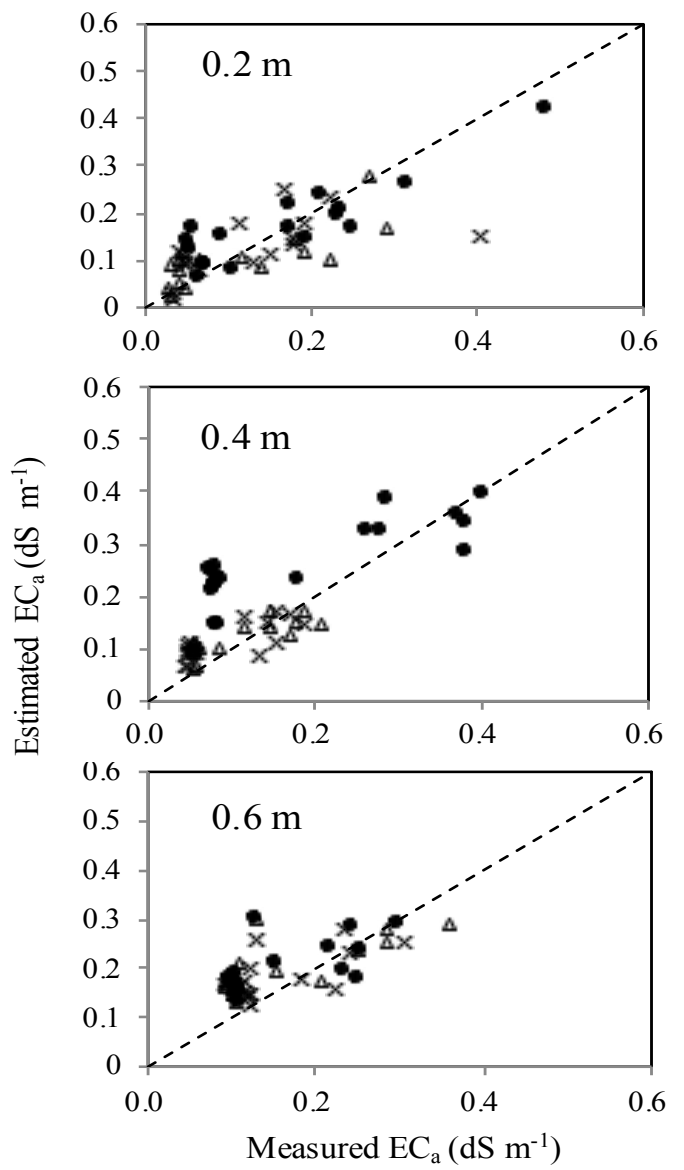

Fig. 3. Measured and estimated apparent electrical conductivity $\left(E C_{a}\right)$ of each TDR probe for each depth, the closed circle, the open triangle and the cross representing TDR probes.

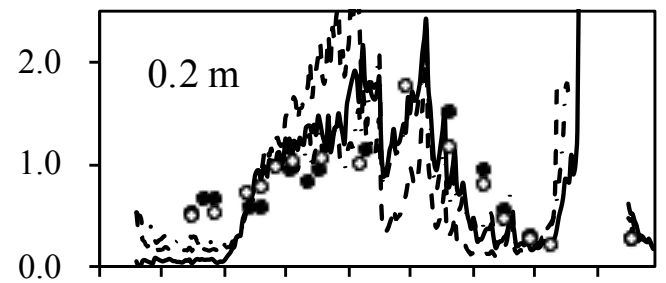

Dec Jan Feb Mar AprMay Jun Jul Aug

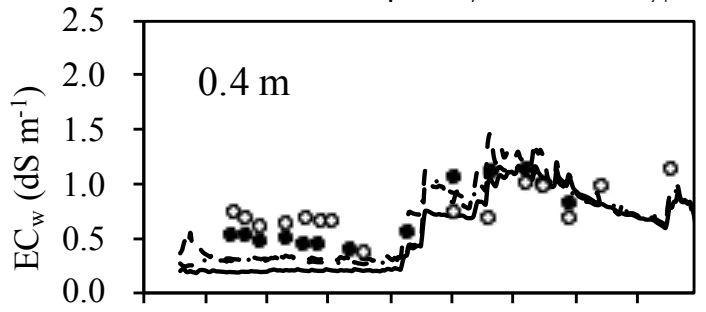

Dec Jan Feb Mar AprMav Jun Jul Aue

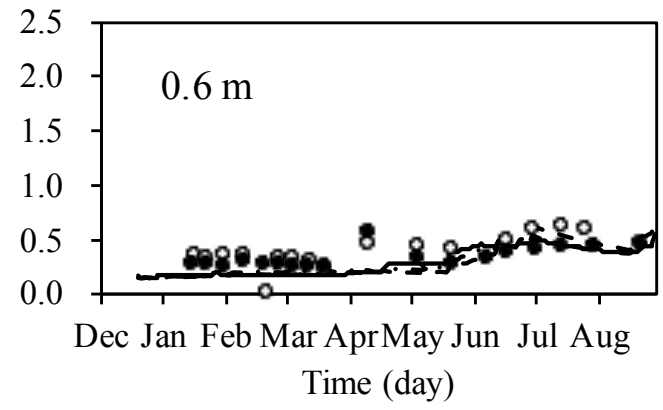

Fig. 4. Estimated $E C_{w}$ (solid line, dashed line and chain line, each representing a TDR probe) and the measured $E C_{w}$ of the extracted soil solutions (the closed and open circles representing suction cups). 
fluctuation of the estimated $E C_{w}$ was very large (note that the data gap from mid-July to mid-August at the top panel in Fig. 4 was caused by unreasonable calculation results of the $E C_{w}$ ), and RMSE was $0.34,0.57,0.68 \mathrm{dS} \mathrm{m}^{-1}$ for each probe. This was because the range of $\theta$, when the soil solution was sampled, was too narrow as compared to the range of $\theta$ measured by TDR probes. As shown in Fig. 5, $\theta$ ranged from 0.40 to 0.57 in the field, while the extracted soil solution was in the $\theta$ range of 0.46 to 0.55 (the corresponding TDR measurement values). The soil solution was not extracted in the period of mid-July to mid-August, when the soil was relatively dry $(0.40<\theta<0.46)$. When the field data of $\theta$ exceeded the fitted range, the estimated $E C_{w}$ took unrealistic values. In some cases, the estimated $E C_{w}$ had negative values (from mid-July to mid-August). In the topsoil layer of $0.4 \mathrm{~m}$, and the subsoil layer of $0.6 \mathrm{~m}$, the discrepancy in the range of $\theta$ was not severe as compared to that at $0.2 \mathrm{~m}$, and the estimation of $E C_{w}$ at 0.4 and $0.6 \mathrm{~m}$ depth was more stable than the data obtained at a depth of $0.2 \mathrm{~m}$; RMSE was $0.27,0.22$ and $0.42 \mathrm{dS} \mathrm{m}^{-1}$ for probes at a depth of $0.4 \mathrm{~m}$, and $0.12,0.12$ and $0.18 \mathrm{dS} \mathrm{m}^{-1}$ for probes at a depth of $0.6 \mathrm{~m}$. Compared with the estimation made by Miyamoto et al. (2015), which yielded RMSE of 0.42, 0.29 and $0.42 \mathrm{dS} \mathrm{m}^{-1}$ for probes at a depth of $0.4 \mathrm{~m}$, and 0.38 , 0.33 and $0.21 \mathrm{dS} \mathrm{m}^{-1}$ for probes at a depth of $0.6 \mathrm{~m}$, the estimation with the proposed method was more close to the field-obtained data, especially at a depth of $0.6 \mathrm{~m}$.

Figure 4 shows that the proposed method worked fine with the subsoil layer but did not work at a depth of $0.2 \mathrm{~m}$ as well as expected. The main reason for failure was that we could not extract the soil solution from dry soil. Especially at the driest period of mid-July to midAugust, the water content reached $\theta=0.40$ at topsoil and $\theta=0.46$ at subsoil, corresponding to $100 \mathrm{kPa}$ matric suction (Fig. 1). Extracting the soil solution of such high matric suction through porous cups proved difficult.

We tried to overcome this difficulty (i.e. the unavailability of the dry soil solution) by adding a small amount of experimental data for our analysis. Note that in the laboratory experiment the soil solution was centrifuged and data were available for lower water contents when compared to the field data. As our method aims at reducing the workload required for a laboratory experiment to be performed, we only introduced 2 data sets, i.e. (1) dry soil with small $E C$ and (2) wet soil with high $E C$. Based on the laboratory data provided by Miyamoto et al. (2015), we used these 2 data points; (1) $\theta=0.35, E C_{a}=0.030 \mathrm{dS} \mathrm{m}^{-1}, E C_{w}=0.49$ $\mathrm{dS} \mathrm{m}^{-1}$ (2) $\theta=0.60, E C_{a}=1.20 \mathrm{dS} \mathrm{m}^{-1}, E C_{w}=3.94 \mathrm{dS} \mathrm{m}^{-1}$. In addition to 17 data points from the field, 2 data points from the laboratory experiment were used for estimating the Rhoades parameter sets. For compensating the numbers of data points in the laboratory, as compared to the field data, weights $\left(w_{i}\right.$ in Eq. (7)) were set as 3 for the laboratory data and 1 for the field data.

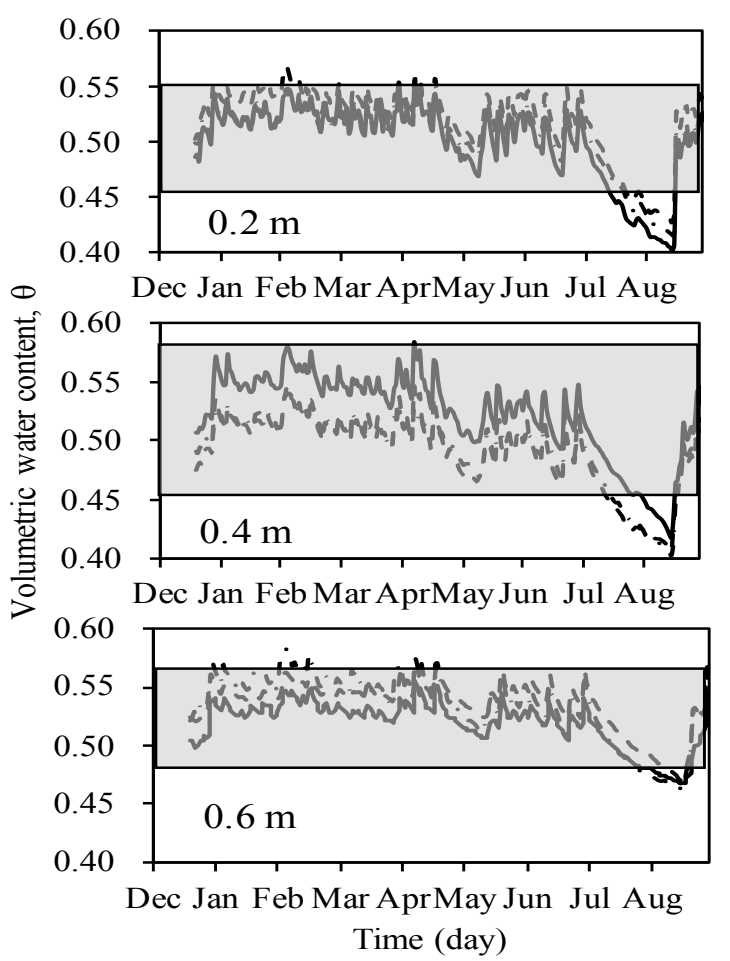

Fig. 5. Volumetric water content measured at depths of $0.2,0.4$ and $0.6 \mathrm{~m}$ in three TDR locations (the solid line, the dashed line and the chain line representing TDR probes). The shadow area shows the range of the volumetric water content (the corresponding TDR value) of the extracted soil solution.

Table 2. Estimated parameters with field extracted soil solution and field measured TDR data, with supplementary laboratory data at dry and wet conditions

\begin{tabular}{lccc}
\hline Depth & \multicolumn{3}{c}{$0.2 \mathrm{~m}$} \\
\hline Probe ID & $2 \mathrm{~A}$ & $2 \mathrm{~B}$ & $2 \mathrm{C}$ \\
\hline$a$ & 2.0421 & 1.8905 & 2.1467 \\
$b$ & -0.7269 & -0.6339 & -0.7814 \\
$E C_{s}$ & 0.0304 & 0.0000 & 0.0000 \\
\hline
\end{tabular}

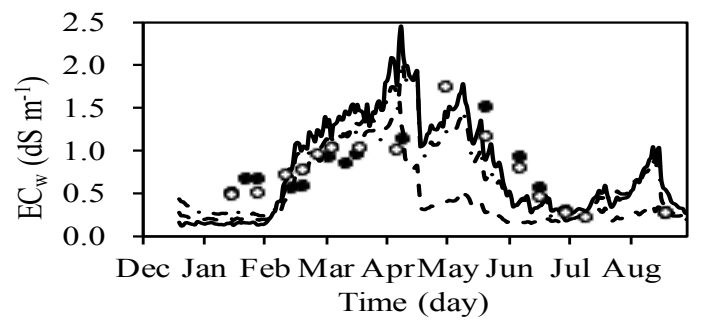

Fig. 6. estimated $E C_{w}$ (the solid line, the dashed line and the chain line representing TDR probes) and the measured $E C_{w}$ of the extracted soil solutions (the closed and open circles representing suction cups) at a depth of $0.2 \mathrm{~m}$, estimated with the field extracted soil solution and laboratory data under dry and wet conditions. 


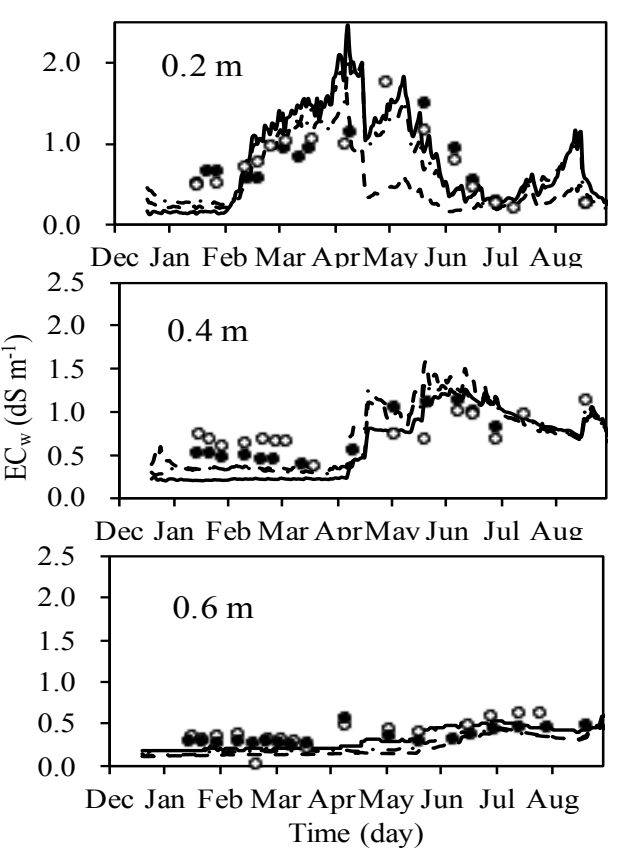

Fig. 7. Estimated $E C_{w}$ (the solid line, the dashed line and the chain line representing TDR probes) and the measured $E C_{w}$ of the extracted soil solutions (the closed and open circles representing suction cups), estimated from a reduced set of field data. At a depth of $0.2 \mathrm{~m}$, laboratory data under dry and wet condition was also used.

The parameter set at the topsoil layer $(0.2 \mathrm{~m}$ depth) estimated in this modified method is shown in Table 2. Figure 6 shows the change in the estimated $E C_{w}$, calculated from $\theta$ and $E C_{a}$ measured with TDR probes, and parameters in Table 2, when compared with to the $E C_{w}$ directly measured from the soil solution. The estimated curve is more stable than in Fig. 4, where no laboratory data was used. RMSE was $0.37,0.50$ and $0.53 \mathrm{dS} \mathrm{m}^{-1}$ for each probe.

Figure 7 shows a similar result as in Fig. 4, but with a reduced set of field data; 8 data were included out of full dataset comprising 17 entries. As for a depth of $0.2 \mathrm{~m}$, the same data from the laboratory experiment, as shown in Fig. 6 , i.e., the two datasets of the dry and wet soils, were also used in the analysis. Weights were set as 1 for both the field and laboratory data. The estimated parameter in this figure is summarised in Table 3. By comparing the curves of Fig. 4 (for depths of $0.4 \mathrm{~m}$ and $0.6 \mathrm{~m}$ ) and Fig. 6 (for a depth of $0.2 \mathrm{~m}$ ) with Fig. 7, the estimated curves represent the measured data equally well. In other words, decreasing the measured data from 17 to 8 did not significantly deteriorate the estimation, as the reduced data included the driest data in mid-July and, therefore, the range of the water content of the reduced dataset was similar to that of the whole data.

In Figs 7, 8 data out of the full set of 17 data were used. The remaining 9 data were used for the validation set. RMSE for the estimated $E C_{w}$ for the validation set was $0.41,0.50$ and $0.35 \mathrm{dS} \mathrm{m}^{-1}$ for probes at a depth of $0.2 \mathrm{~m}$, $0.27,0.25$ and $0.23 \mathrm{dS} \mathrm{m}^{-1}$ for probes at a depth $0.4 \mathrm{~m}$ depth, and $0.09,0.12$ and $0.09 \mathrm{dS} \mathrm{m}^{-1}$ for probes at a depth of $0.6 \mathrm{~m}$. This result was not particularly higher than the RMSE of the estimation from the whole set of data; in some of the probes, RMSE got smaller. Therefore, it was confirmed that the estimation of Fig. 7 did not deteriorate from Figs 4 and 6 although the numbers of data were reduced from 17 to 8 .

As we have shown in the reduced set of field data, increasing the numbers of data points (from 8 to17) does not always improve the estimation. The estimation can be improved by using as wide range of water content as possible, from dry soil to wet soil, to minimise the discrepancy of the fitted range of water content and the monitored range of water content, as shown in Fig. 5. When it is technically difficult to obtain a wide range of water content, laboratory data under extreme water content conditions can be used to form an additional dataset, as shown in Fig. 6.

The estimation of $E C_{w}$ based on the parameter set determined under laboratory conditions (Fig. 3 in Miyamoto et al., 2015) was improved with the proposed method, which uses the parameter set determined directly from the field-obtained value. For example, in Miyamoto's estimation, the $\mathrm{NO}_{3}-\mathrm{N}$ concentration at a depth of $0.6 \mathrm{~m}$ was twice as large as the $\mathrm{NO}_{3}-\mathrm{N}$ concentration measured with the extracted soil solution because $E C_{w}$ rose twice as much as the soil solution $E C_{w}$. In the proposed method, the highest value of the estimated $E C_{w}$ was similar to that of the measured $E C_{w}$ value. Therefore, a more realistic value of $\mathrm{NO}_{3}-\mathrm{N}$ can be obtained by the proposed method.

This is because the parameters estimated in the proposed method (Table 1) reflect the properties found under the sitespecific heterogeneous condition, and they are different from the parameters shown in Miyamoto et al. (2015); they are soil-specific parameters determined through a laboratory experiment. Therefore, the parameter set obtained at

Table 3. Estimated parameters with reduced numbers of field data

\begin{tabular}{lcccccccccc}
\hline Depth & \multicolumn{3}{c}{$0.2 \mathrm{~m}^{*}$} & \multicolumn{3}{c}{$0.4 \mathrm{~m}$} & \multicolumn{3}{c}{$0.6 \mathrm{~m}$} \\
\hline Probe ID & $2 \mathrm{~A}$ & $2 \mathrm{~B}$ & $2 \mathrm{C}$ & $4 \mathrm{~A}$ & $4 \mathrm{~B}$ & $4 \mathrm{C}$ & 6A & $6 \mathrm{~B}$ & $6 \mathrm{C}$ \\
\hline$a$ & 2.1132 & 2.1481 & 2.2485 & 0.8123 & 0.2586 & 0.2307 & 0.0000 & 0.0890 & 0.0003 \\
$b$ & -0.7660 & -0.7975 & -0.8430 & 0.2431 & 0.1851 & 0.1780 & 1.0088 & 1.3214 & 1.2144 \\
$E C_{s}$ & 0.0304 & 0.0001 & 0.0000 & 0.0000 & 0.0000 & 0.0000 & 0.0002 & 0.0002 & 0.0000 \\
\hline
\end{tabular}

*Laboratory data at dry and wet condition was also used. 
one field site by using this method should not be used for other field sites even if the soil properties are similar. The parameters determined are not soil-specific but site-specific values.

\section{CONCLUSIONS}

1. Compared to the conventional method of estimating Rhoades parameters through a laboratory experiment, the method proposed in this study, where Rhoades parameters are estimated based on the field-monitored values of the time domain reflectometry and the field-extracted soil solution, can give better estimates of soil solution electrical conductivity. The method is reliable since it is based on the actual soil solution electrical conductivity values measured in the field. It was made possible because our method determines the initial parameter set for nonlinear regression systematically and does not require a 2-step linear regression process as the one performed in the conventional method.

2. The key to success in this method is to obtain the soil solution of a wide range of water content. When a sufficiently wide range of water content is not available in the field, a small amount of supplementary data obtained under laboratory conditions can be added to widen the calibration range.

3 . When researchers, engineers or farmers want to estimate the soil solution electrical conductivity accurately without much effort, the method proposed here may be useful for them provided that they can access the field data of the soil solution electrical conductivity easily.

Conflict of interest: The authors do not declare any conflict of interest. There is a patent pending in Japan (application number: 2018-080205) for the method described in this paper. There are no other patents.

\section{REFERENCES}

Baumgartner N., Parkin G.W., and Elrick D.E., 1994. Soil water content and potential measured by hollow time domain reflectometry probe. Soil Sci. Soc. Am. J., 58, 315-318.

Das B.S., Wraith J.M., and Inskeep W.P., 1999. Nitrate concentrations in the root zone estimated using time domain reflectometry. Soil Sci. Soc. Am. J., 63, 1561-1570.

De Neve S., van de Steene S., Hartmann R., and Hofman G., 2000. Using time domain reflectometry for monitoring mineralization of nitrogen from soil organic matter. European J. Soil Sci., 51(2), 295-304.

Gupta S.C. and Hanks R.J., 1972. Influence of Water content on electrical conductivity of the soil. Soil Sci. Soc. Am. Proc., $36,855-857$.

Heimovaara T.J., 1995. Assessing temporal variations in soil water composition with time domain reflectometry. Soil Sci. Soc. Am. J., 59, 689-698.

Hilhorst M.A., 2000. A pore water conductivity sensor. Soil Sci. Soc. Am. J., 64, 1922-1925.
IUSS Working Group, 2014. World reference base for soil resources 2014 international soil classification system for naming soils and creating legends for soil maps. FAO, Rome.

Malicki M.A. and Walczak R.T., 1999. Evaluating soil salinity status from bulk electrical conductivity and permittivity. European J. Soil Sci., 50, 505-514.

Mallants D., Vanclooster M., Toride N., Vanderbrorght J., van Genuchten M.Th. and Feyen J., 1996. Comparison of three methods to calibrate TDR for monitoring solute movement in unsaturated soil. Soil Sci. Soc. Am. J., 60, 747-754.

Marquardt D.W., 1963. An algorithm for least-square estimation of nonlinear parameters. J. Soc. Industrial Appl. Mathematics, 11(2), 431-441.

Miyamoto T., Kameyama K., and Iwata Y., 2015. Monitoring electrical conductivity and nitrate concentrations in an Andisol field using time domain reflectometry. Japan Agric. Res. Quarterly, 49(3), 261-267.

Mualem Y. and Friedman S.P., 1991. Theoretical prediction of electrical conductivity in saturated and unsaturated soil. Water Res. Res., 27, 2771-2777.

Muñoz-Carpena R., Regalado, C.M., Ritter A., Alvarez-Benedi J., and Socorro A.R., 2005. TDR estimation of electrical conductivity and saline solute concentration in a volcanic soil. Geoderma, 124, 399-413.

Noborio K., 2001. Measurement of soil water content and electrical conductivity by time domain reflectometry: a review. Computers and Electronics in Agriculture, 36, 113-132.

Risler P.D., Wraith J.M., and Gaber H.M., 1996. Solute transport under transient flow conditions estimated using time domain refrectometry. Soil Sci. Soc. Am. J., 60, 1297-1305.

Rhoades J.D., Manteghi N.A., Shouse P.J., and Alves W.J., 1989. Soil electrical conductivity and soil salinity: New formulations and calibrations. Soil Sci. Soc. Am. J., 53, 433-439.

Rhoades J.D., Raats P.A., and Prather R.J., 1976. Effects of liquid-phase electrical conductivity, water content, and surface conductivity on bulk soil electrical conductivity. Soil Sci. Soc. Am. J., 40, 651-655.

Scudiero E., Berti A., Teatini P., and Morari F., 2012. Simultaneous monitoring of soil water content and salinity with a low-cost capacitance-resistance probe. Sensors, 12, 17588-17607.

Seki K., 2007. SWRC fit - a nonlinear fitting program with a water retention curve for soils having unimodal and bimodal pore structure. Hydrology Earth System Sci. Discussions, 4(1), 403-437.

Šimůnek J. and Hopmans J.W., 2002. Parameter Optimization and Nonlinear Fitting. in Methods of Soil Analysis: Part 4 Physical Methods, 139-158. Soil Science Society of America, Madison, WIS, USA.

Vaz C.M.P., Jones S., Meding M., and Tuller M., 2013. Evaluation of standerd calibration function for eight electromagnetic soil moisture sensors. Vadose Zone J., 12(2), doi: $10.2136 /$ vzj2012.0160.

Wilczek A., Szypłowska A., Skierucha W., Cieśla J., and Pichler V., Janik G., 2012. Determination of soil pore water salinity using an FDR sensor working at various frequencies up to $500 \mathrm{MHz}$. Sensors, 12, 10890-10905. 